\title{
Antagonizing the parathyroid calcium receptor stimulates parathyroid hormone secretion and bone formation in osteopenic rats
}

\author{
Maxine Gowen, ${ }^{1}$ George B. Stroup, ${ }^{1}$ Robert A. Dodds, ${ }^{1}$ Ian E. James, ${ }^{1}$ Bart J. Votta, ${ }^{1}$ \\ Brian R. Smith, ${ }^{2}$ Pradip K. Bhatnagar, ${ }^{3}$ Amparo M. Lago, ${ }^{3}$ James F. Callahan, ${ }^{3}$ \\ Eric G. DelMar, ${ }^{4}$ Michael A. Miller, ${ }^{4}$ Edward F. Nemeth, ${ }^{4}$ and John Fox ${ }^{4}$ \\ ${ }^{1}$ Department of Bone and Cartilage Biology, \\ ${ }^{2}$ Department of Drug Metabolism, and \\ ${ }^{3}$ Department of Medicinal Chemistry, SmithKline Beecham Pharmaceuticals Inc., King of Prussia, Pennsylvania, USA \\ ${ }^{4}$ NPS Pharmaceuticals Inc., Salt Lake City, Utah, USA
}

Address correspondence to: John Fox, NPS Pharmaceuticals Inc., 420 Chipeta Way, Salt Lake City, Utah 84108, USA. Phone: (801) 583-4939; Fax: (801) 583-4961; E-mail: jfox@npsp.com.

Parts of this work were presented at the Second Joint Meeting of the American Society for Bone and Mineral Research and the International Bone and Mineral Society, San Francisco, California, USA, December 1-6, 1998, and have appeared in abstract form (1998. Bone. 23[Suppl.]:S163).

Received for publication December 2, 1999, and accepted in revised form April 19, 2000.

Parathyroid hormone (PTH) is an effective bone anabolic agent, but it must be administered parenterally. An orally active anabolic agent would provide a valuable alternative for treating osteoporosis. NPS 2143 is a novel, selective antagonist (a "calcilytic") of the parathyroid cell $\mathrm{Ca}^{2+}$ receptor. Daily oral administration of NPS 2143 to osteopenic ovariectomized (OVX) rats caused a sustained increase in plasma PTH levels, provoking a dramatic increase in bone turnover but no net change in bone mineral density. Concurrent oral administration of NPS 2143 and subcutaneous infusion of $17 \beta$-estradiol also resulted in increased bone turnover. However, the antiresorptive action of estrogen decreased the extent of bone resorption stimulated by the elevated PTH levels, leading to an increase in bone mass compared with OVX controls or to either treatment alone. Despite the sustained stimulation to the parathyroid gland, parathyroid cells did not undergo hyperplasia. These data demonstrate that an increase in endogenous PTH secretion, induced by antagonism of the parathyroid cell $\mathrm{Ca}^{2+}$ receptor with a small molecule, leads to a dramatic increase in bone turnover, and they suggest a novel approach to the treatment of osteoporosis.

J. Clin. Invest. 105:1595-1604 (2000).

\section{Introduction}

Osteoporosis is a serious and prevalent disease associated with significant mortality and morbidity, particularly after hip fracture (1). Osteoporotic fractures are a significant health problem, estimated to cost $\$ 13.8$ billion in the United States in 1995 (2). Currently available therapies such as estrogen, raloxifene, calcitonin, and bisphosphonates prevent further bone loss by inhibiting bone resorption. These can lead to a significant reduction in fracture risk. However, these antiresorptive therapies reduce the risk of fracture by only $40-50 \%$, at best. The ability to enhance bone formation and to increase bone mass to levels approaching the young adult mean would represent a significant advance in the treatment of osteoporosis. Parathyroid hormone $(\mathrm{PTH})$ is the most widely studied bone anabolic agent $(3,4)$. Intermittent treatment of both rats $(3,5-7)$ and osteoporotic men and women $(4,8-13)$ with PTH increases bone mass and strength markedly, without significant adverse effects. Unfortunately, PTH must be administered parenterally; to date this has been restricted to subcutaneous injection in humans. This is far from ideal for a chronic therapy.

The control of PTH secretion by extracellular $\mathrm{Ca}^{2+}$ is mediated by a $\mathrm{Ca}^{2+}$ receptor expressed on the surface of parathyroid cells (14). The cloning and characterization of the bovine form of this $G$ protein-coupled receptor was first described by Brown and colleagues (15). Subsequently, the human homologue was isolated (16). This receptor is negatively coupled to PTH secretion, such that increasing the concentration of extracellular ligand $\left(\mathrm{Ca}^{2+}\right)$ leads to inhibition of PTH secretion. Numerous natural activating and inactivating mutations in the human $\mathrm{Ca}^{2+}$ receptor have been identified and linked to several disorders of calcium metabolism (17). Recently, small molecule activators of the $\mathrm{Ca}^{2+}$ receptor (calcimimetics) have been identified that inhibit PTH secretion in vitro $(18,19)$ and in patients with primary or secondary hyperparathyroidism $(20,21)$.

It has been proposed that an antagonist of the $\mathrm{Ca}^{2+}$ receptor (a calcilytic) would mimic a state of hypocalcemia and stimulate PTH secretion. The resulting tran- 
sient increases in circulating PTH levels, if repeated on a daily basis, might produce an anabolic effect in bone (14). We showed previously that the induction of hypocalcemia by infusion of the calcium chelator EGTA raised circulating PTH to levels that were sufficient to stimulate bone formation in osteopenic rats (22). If this could be achieved with an orally active small molecule antagonist of the $\mathrm{Ca}^{2+}$ receptor, it might represent a novel anabolic therapy for osteoporosis. The identification and pharmacological characterization of such a molecule, NPS 2143, has recently been described (23). Briefly, screening of compound libraries in human embryonic kidney (HEK 293) cells that stably express the human parathyroid $\mathrm{Ca}^{2+}$ receptor identified a compound that was a weak $\left(\mathrm{IC}_{50}=11 \mu \mathrm{M}\right)$ inhibitor of increases in cytoplasmic $\mathrm{Ca}^{2+}$ levels induced by extracellular $\mathrm{Ca}^{2+}$. Structural modification of this compound yielded NPS 2143, a more potent $\left(\mathrm{IC}_{50}=43 \mathrm{nM}\right)$ and selective compound (Figure 1). In particular, NPS 2143 did not inhibit cytoplasmic $\mathrm{Ca}^{2+}$ responses to glutamate in HEK 293 cells engineered to express the structurally related metabotropic glutamate receptors, or to $\gamma$-amino butyric acid (GABA) in similar cells expressing similarly related $G_{A B A}$ receptors (24). Moreover, NPS 2143 stimulated PTH secretion from bovine parathyroid cells in vitro $\left(\mathrm{EC}_{50}=39 \mathrm{nM}\right)$ and increased plasma PTH levels when administered to normal rats by intravenous infusion. Here we describe the effect of daily oral administration of NPS 2143 on bone in aged ovariectomized (OVX) rats with established osteopenia, and demonstrate for the first time that antagonism of the parathyroid cell $\mathrm{Ca}^{2+}$ receptor in vivo by an orally active small molecule leads to an increase in bone turnover.

\section{Methods}

\section{OVX rat studies}

Animals, diets, and surgery. Animal protocols were approved by the Animal Care and Use Committee at SmithKline Beecham Pharmaceuticals Inc. Six-monthold virgin Sprague-Dawley rats were purchased from Charles River Laboratories Inc. (Wilmington, Massachusetts, USA). They were provided with unrestricted access to tap water and commercial rodent chow (Diet 5001; PMI Nutrition International, Brentwood, Missouri, USA) throughout the study. When the rats were 7 months old, they were subjected either to a bilateral ovariectomy or to sham surgery, and then held for a further 3 months to allow the development of osteopenia. At that time, each rat was anesthetized with isoflurane, and bone mineral density (BMD) was quantified in the lumbar spine, distal femur, and proximal tibia by dual-energy x-ray absorptiometry (QDR-4500A; Hologic Inc., Waltham, Massachusetts, USA).

Study 1. The OVX rats were divided into 3 groups $(n=$ 10-14 per group) that were matched by lumbar BMD. One group of sham-operated rats $(n=10)$ and one group of OVX rats received a daily oral dose by gavage of the same vehicle $(5 \mathrm{~mL} / \mathrm{kg})$ used to formulate NPS 2143 , a $20 \%$ aqueous solution of 2-hydroxypropyl- $\beta-$ cyclodextrin (Cerestar, Hammond, Indiana, USA). The second OVX group received NPS $2143(100 \mu \mathrm{mol} / \mathrm{kg}$, peros), and the third OVX group received subcutaneous injection $(5 \mu \mathrm{g} / \mathrm{kg})$ of synthetic rat PTH(1-34) (Bachem California, Torrance, California, USA), dissolved in $2 \%$ cysteine- $\mathrm{HCl}, \mathrm{pH} 4.5$, containing $0.1 \%$ BSA. The dose of NPS 2143 was chosen because preliminary studies in normal rats showed that it induced a consistent and maximal increase in plasma PTH levels. The $5 \mu \mathrm{g} / \mathrm{kg}$ dose of PTH was shown previously to be an effective anabolic dose in OVX rats, and to increase plasma PTH levels by an amount similar to that achievable by acute stimulation of PTH secretion (22).

Treatment continued daily for 8 weeks. BMD was again determined in vivo at treatment weeks 4 and 8 . All animals received calcein $(10 \mathrm{mg} / \mathrm{kg}$, subcutaneously) 10 days and 3 days before sacrifice. At the end of the study, animals (3-4 at each time point) were sacrificed at varying times after the final dose, and blood was collected for PTH analysis. The tibiae were removed for histomorphometric analysis.

Study 2. Animals were prepared as described in Study 1 . Groups consisted of sham-operated and OVX controls that received vehicle (20\% 2-hydroxypropyl- $\beta$ cyclodextrin, per os), and three additional OVX groups that received either NPS $2143(100 \mu \mathrm{mol} / \mathrm{kg}$, per os); $17 \beta$-estradiol, administered as a continuous infusion using a subcutaneously implanted pellet $(0.01 \mathrm{mg}$ per 90 days; Innovative Research of America, Sarasota, Florida, USA); or NPS 2143 together with $17 \beta$-estradiol. Dosing continued daily for 5 weeks. BMD was determined in vivo at baseline and at the end of the study. All rats received calcein $(10 \mathrm{mg} / \mathrm{kg}$, subcutaneously) at 10 days and 3 days before sacrifice, at which point the tibiae were collected for histomorphometric analysis. To evaluate the effects of treatment on parathyroid cell proliferation, five animals in each treatment group were infused with 5-bromo- 2 'deoxyuridine (BrdU), a thymidine analogue. Model 2001 Alzet osmotic minipumps (ALZA Corp., Palo Alto, California, USA) were filled with BrdU (250 $\mathrm{mg} / \mathrm{mL}$ ) dissolved in dimethyl sulfoxide and propylene glycol (1:1 vol/vol), and implanted subcutaneously 4 days before necropsy.

Bone histomorphometry. Bone samples from both studies were dehydrated with increasing concentrations of ethanol, defatted in acetone, and embedded in methyl methacrylate (Polysciences Inc., Warrington, Pennsylvania, USA). Longitudinal undecalcified sections (5 $\mu \mathrm{m})$ of the proximal tibia were cut on a Leica microtome (SM2500S; Leica Microsystems Inc., Deerfield, Illinois, USA). In Study 1, sections were stained with von Kossa stain; in Study 2 the tissue blocks were prestained with Villanueva stain (25). Histomorphometric analysis was carried out in a blinded fashion, using the Optimus system (Optimus Corp., Seattle, Washington, USA) in Study 1 and the Osteomeasure system (Osteometrics 
<smiles>CC(C)(Cc1ccc2ccccc2c1)NC[C@H](O)COc1cccc(Cl)c1C#N</smiles>

Figure 1

Structure of NPS 2143

Inc., Decatur, Georgia, USA) in Study 2. Measurements within the tibial metaphysis were restricted to a mean tissue area of approximately $8 \mathrm{~mm}^{2}$, beginning $1 \mathrm{~mm}$ below the growth plate. Primary measurements included total bone and marrow area (B.Ar, $\mathrm{mm}^{2}$ ), trabecular bone area $\left(\mathrm{Tb} . \mathrm{Ar}, \mathrm{mm}^{2}\right)$, bone perimeter $(\mathrm{mm})$, singleand double-labeled perimeter (sL.Pm, dL.Pm; mm), osteoid perimeter (O.Pm, mm), and eroded perimeter (E.Pm, mm). Derived indices included Tb.Ar (\%), trabecular number (Tb.N, $\mathrm{mm}^{-1}$ ), trabecular thickness (Tb.Th, $\mu \mathrm{m}$ ), trabecular separation (Tb.Sp, $\mu \mathrm{m}$ ), mineral appositional rate (MAR, $\mu \mathrm{m} /$ day), and labeled perimeter (L.Pm, \%). Also included were bone formation rate (BFR) indices designated surface-referent (BFR/Tb.Pm, $\mu \mathrm{m}^{3} / \mu \mathrm{m}^{2} /$ year), area-referent (BFR/Tb.Ar, $\%$ per year), and tissue-referent (BFR/B.Ar, \% per year). All nomenclature and abbreviations are consistent with those recommended by the American Society for Bone and Mineral Research (26).

\section{Parathyroid cell proliferation}

Tissue processing. The thyroid/parathyroid complex and ileum were collected at necropsy and fixed for 24 hours at $4{ }^{\circ} \mathrm{C}$ with $10 \%$ phosphate-buffered formalin. After sequential dehydration with ethanol and xylene, the tissues were embedded in Surgipath EM-400 (Surgipath Medical Industries Inc., Richmond, Illinois, USA). The thyroid/parathyroid complex with a portion of the adjoining trachea was cut into $3-\mu \mathrm{m}$-thick sections in the sagittal plane. The sections quantified were taken from the most central areas of the parathyroid gland. The ileum was cut into $3-\mu \mathrm{m}$-thick cross-sections.

Immunohistochemistry. To identify proliferating cells, BrdU-incorporated cells were detected using a BrdU immunostaining kit (Zymed Laboratories Inc., San Francisco, California, USA). After the slides were dewaxed and rehydrated, slides were incubated for 10 minutes with 3\% hydrogen peroxide and methanol to block endogenous peroxidase. Slides were digested with $0.1 \%$ trypsin for 15 minutes at $37^{\circ} \mathrm{C}$, rinsed with distilled water, and incubated with denaturing solution for 30 minutes at room temperature to denature DNA. Slides were then reacted with anti-BrdU monoclonal antibody at room temperature for 1 hour. The bound primary antibody was detected by the streptavidinbiotin immunoperoxidase method. Slides were developed with 3,3'-diaminobenzidine and counterstained with hematoxylin. BrdU was identified as dark brown staining in the nucleus. A Zymed BrdU-positive mouse intestine slide was used as a negative control by replacing the anti-BrdU monoclonal antibody with distilled water for detection of nonspecific binding.

Cell counting. Positive BrdU incorporation for each animal was confirmed in the epithelial cells of the ileum. For each animal, three separate slides of the parathyroid gland were quantified, and the total number of positive- and negative-staining nuclei were determined. The number of BrdU-positive and BrdU-negative cells were quantified at $\times 200$, and were expressed as a percentage of total cell number.

\section{In vitro assays of osteoblast and osteoclast activity}

The TF274 cell line, derived from immortalized human bone marrow stromal cells (27) and primary cultures of osteoblasts derived from explants of human trabecular bone (28), were used to assess some functional responses of osteoblasts. First, the effect of NPS 2143 on PTH receptor-mediated increases in cyclic AMP formation was quantified. Both cell types were incubated in quadruplicate with human PTH(1-34) $(40 \mathrm{ng} / 200 \mu \mathrm{L})$ for 30 minutes at room temperature in the absence or presence of $0.1,1.0$, or $10.0 \mu \mathrm{mol} / \mathrm{L}$ NPS 2143 . Reactions were terminated by acidifying the medium, and cellular lysis was facilitated by freezing. After thawing and centrifugation, cyclic AMP levels were determined in neutralized supernatants using a nonradioactive assay kit (Amersham Life Sciences Inc., Arlington Heights, Illinois, USA). TF274 cells were also used to assess the effects of NPS 2143 on alkaline phosphatase activity. Cells grown to confluence in Ham's F-12 medium containing $1 \% \mathrm{FCS}$ were incubated at $37^{\circ} \mathrm{C}$ for 48 hours in the absence or presence of PTH $(20 \mathrm{ng} / 0.5 \mathrm{~mL})$, and

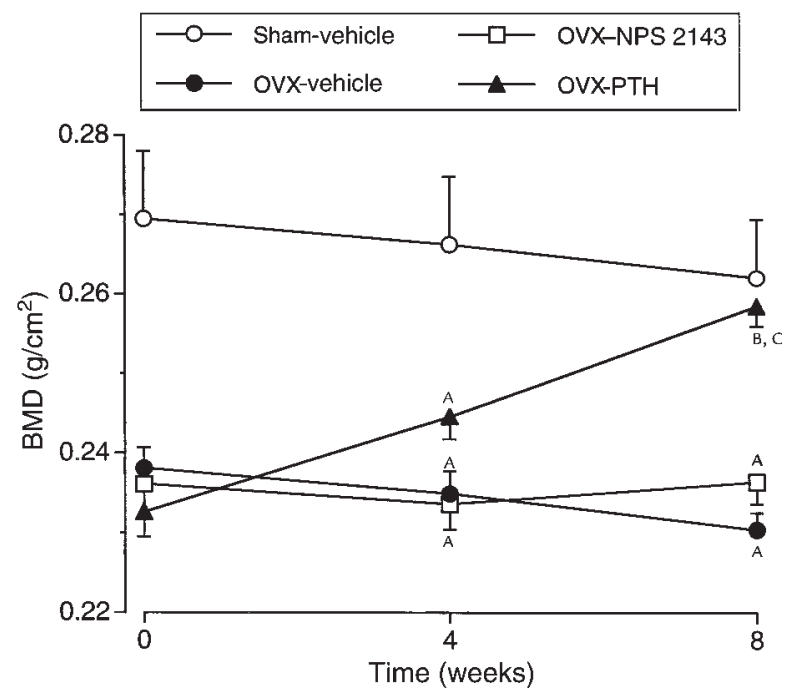

\section{Figure 2}

Effect of daily administration of NPS $2143(100 \mu \mathrm{mol} / \mathrm{kg}$, per os $)$ or rat PTH(1-34) $(5 \mu \mathrm{g} / \mathrm{kg}$, subcutaneously) on bone mineral density (BMD) in the proximal tibia of osteopenic OVX rats. Values shown

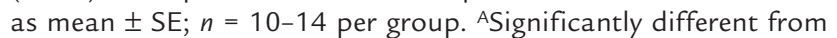
sham-vehicle; $P<0.05$. BSignificantly different from OVX-vehicle; $P<0.05$. CSignificantly different from OVX-NPS 2143; $P<0.05$. 


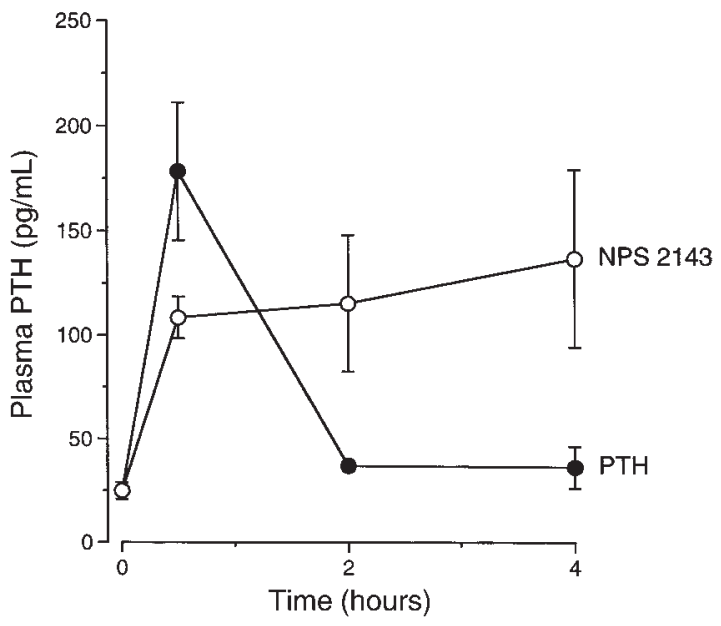

Figure 3

Plasma levels of PTH after the administration of NPS $2143(100$ $\mu \mathrm{mol} / \mathrm{kg}$, per os) or rat PTH(1-34) (5 $\mu \mathrm{g} / \mathrm{kg}$, subcutaneously) to OVX rats. Both endogenous and exogenous PTH levels are of the 1-34 peptide. Values are mean \pm SE; $n=3-4$ per timepoint.

with or without $0.01,0.1$, or $1.0 \mu \mathrm{mol} / \mathrm{L}$ NPS 2143 . Alkaline phosphatase activity appearing in the medium was measured colorimetrically (29).

Human osteoclasts were obtained by disaggregating fresh osteoclastoma tissue (27), and these isolated cells were then mixed with particles of bovine cortical bone as described recently (30). The mixture of cells and bone particles was incubated for 24 hours at $37^{\circ} \mathrm{C}$ in the absence or presence of various concentrations of NPS 2143. After incubation, the levels of the carboxylterminal peptide of the $\alpha 1$ chain of type I collagen in the medium were quantified using a competitive binding enzyme-linked immunoadsorbant assay kit (ref. 31; Osteometer MediTech Inc., Rodovre, Denmark). The results are expressed as percent inhibition of carboxylterminal peptide levels in media derived from osteoclast/bone particle mixtures cultured in the absence of NPS 2143. IC $_{50}$ was determined by manual extrapolation of concentration-response curves.

Fetal rat long bones were used to assess effects of NPS 2143 on bone resorption in a system containing a number of relevant cell types in a more physiological environment (32). Timed-pregnant Sprague-Dawley rats were injected subcutaneously with $200 \mu \mathrm{Ci}$ of ${ }^{45} \mathrm{CaCl}_{2}$ on day 18 of gestation, and were housed overnight before they were anesthetized with InnovarVet (Pittman-Moore, Mundelein, Illinois, USA) before sacrifice by cervical dislocation. The fetuses were removed aseptically, and the radii and ulnae were dissected free of surrounding soft tissue and cartilaginous ends. The bone rudiments were randomly sorted so that four rudiments were used at each concentration of NPS 2143 or vehicle (DMSO) control. The bone rudiments were cultured for 18-24 hours in BGJ medium (Sigma Chemical Co., St. Louis, Missouri, USA) con- taining $0.1 \%$ BSA. Then they were transferred to fresh medium and cultured for an additional 48 hours in the absence or presence of human PTH(1-34) (50 ng/mL) with or without various concentrations of NPS 2143. The ${ }^{45} \mathrm{Ca}$ released into the medium and retained in the bone rudiments (after solubilization in 5\% trichloroacetic acid) was quantified by liquid scintillation spectrometry. The results are expressed as percent ${ }^{45} \mathrm{Ca}$ released from bone rudiments.

Biochemical assays. The concentrations of NPS 2143 in plasma were quantified by liquid chromatography/mass spectrometry (limit of detection, 10 $\mathrm{ng} / \mathrm{mL}$ ). Plasma PTH levels were measured using an $\mathrm{N}$ terminal rat PTH immunoradiometric assay kit that exhibits $100 \%$ cross-reactivity between $\mathrm{PTH}(1-34)$ and PTH(1-84) (Immutopics International LLC, San Clemente, California, USA).

Statistical analyses. All results are shown as mean \pm SE. The data were subjected to ANOVA and Fisher's protected least significant difference test to determine the significance of differences between groups. $P<0.05$ was used to signify a significant difference.

\section{Results}

Study 1: Small but sustained elevation of PTH levels increases bone turnover with no net gain or loss of bone

Animals that had undergone ovariectomy 3 months previously had significantly lower BMD at all three skeletal sites measured. The reductions were $15 \%$ at the lumbar spine and proximal tibia, and $24 \%$ at the distal femur. BMD in the proximal tibia was unaffected by daily treatment with NPS 2143, but was returned to preovariectomy levels after 8 weeks of treatment with PTH (Figure 2). Similar changes were seen in the distal femur and lumbar vertebrae (not shown). Plasma PTH levels

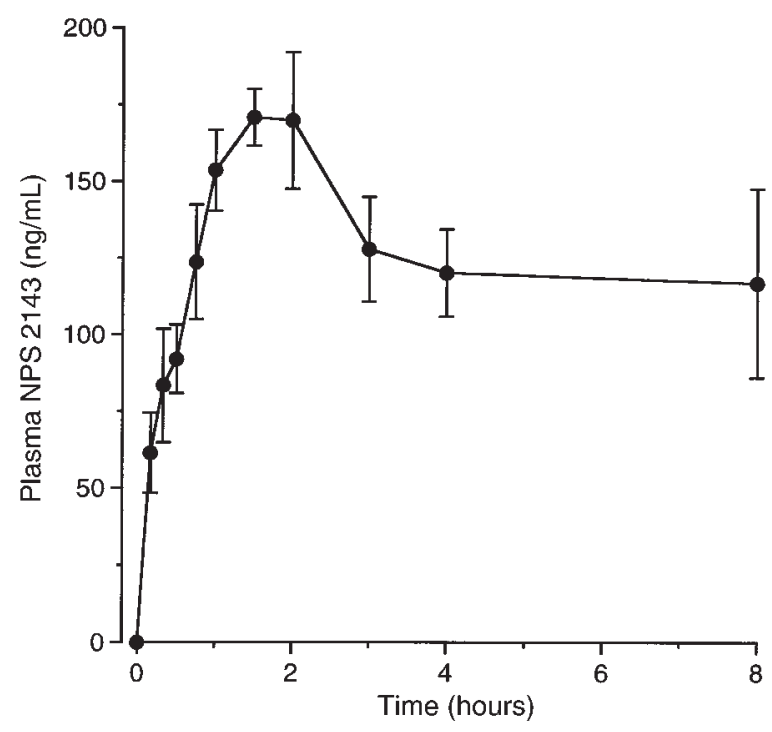

Figure 4

Plasma levels of NPS 2143 after its oral administration (100 $\mu \mathrm{mol} / \mathrm{kg}$ ) to rats. Values are mean $\pm \mathrm{SE} ; n=3$. 
were measured after dosing in the last week of the experiment. PTH levels were elevated (> $100 \mathrm{pg} / \mathrm{mL}$ ) within 30 minutes after dosing with NPS 2143; levels remained high for at least 4 hours (Figure 3). PTH levels in animals given the $5 \mu \mathrm{g} / \mathrm{kg}$ subcutaneous dose of PTH were similar to those dosed with NPS 2143, but had returned to baseline by 2 hours after the injection (Figure 3 ). The differences in the duration of the PTH response can be explained by sustained systemic exposure to NPS 2143, which in a separate experiment was found to be elevated for up to 8 hours after dosing (Figure 4). NPS 2143 levels were undetectable $(<10 \mathrm{ng} / \mathrm{mL})$ at 24 hours.

The different plasma PTH profiles obtained under these two dosing conditions induced markedly different effects on bone turnover. Dynamic histomorphometric analysis of cancellous bone in the proximal tibial metaphysis showed that bone formation (\% O.Pm and \% L.Pm) was further elevated above the OVX control level by both PTH and NPS 2143 (Figure 5). MAR was unaffected by any treatment (data not shown). However, bone resorption, as measured by percent E.Pm, was significantly higher in the NPS 2143 group than in the PTH or OVX control groups. This is exemplified further by the dramatic increase in bone turnover (BFR/B.Ar) in rats treated with NPS 2143 compared with the other two groups (Figure 5). Thus, the modest but prolonged elevation of PTH achieved by administration of NPS 2143 resulted in a dramatic increase in both bone formation and resorption, with no net bone gain or loss. PTH injections also increased both resorption and formation, but formation exceeded resorption, resulting in increased bone mass (Figure 2).

Study 2: Small but sustained elevation of PTH levels in the presence of an antiresorptive agent increases bone turnover with net bone gain

A second study was performed in animals in which NPS 2143 was administered daily for 5 weeks in the presence or absence of estrogen. Figure 6 shows representative sections of proximal tibiae from sham-operated and OVX controls treated with vehicle, an OVX rat treated with $17 \beta$-estradiol alone, and an OVX rat treated with $17 \beta$ estradiol plus NPS 2143 . It is obvious visually that coadministration of NPS 2143 and $17 \beta$-estradiol increased cancellous bone area over and above that achieved with $17 \beta$-estradiol alone. These changes were quantified histomorphometrically; the results are shown in Table 1. Tb.Ar was 72\% lower in OVX animals than in sham-operated animals, a loss that was not significantly restored by treatment with $17 \beta$-estradiol. Treatment with NPS 2143 alone also had no effect on OVX-induced osteopenia. However, NPS 2143 given in combination with $17 \beta$ estradiol resulted in a significant, twofold increase in percent Tb.Ar over the OVX group, an increase that was due primarily to an increase in Tb.Th (Table 1$)$. The apparent small increase in Tb.N in rats given $17 \beta$-estradiol probably resulted from prevention of further cancellous bone loss during the treatment period. Treatment with $17 \beta$-estradiol alone completely reversed the
OVX-induced increases in indices of bone formation and resorption (Figure 7). As was observed in Study 1, treatment with NPS 2143 alone also increased most of these indices above levels in OVX controls. However, in rats treated with NPS 2143 plus $17 \beta$-estradiol, tissue-referent BFR was significantly elevated compared with all other groups (Figure 7). Elevation of bone formation rate/tissue area shows that bone mass was increased in the area measured, reflecting new bone formation on bone surfaces that were not being remodeled, a classic feature of PTH action. This appears to be a result of a decrease in resorption (presumably due to concurrent estrogen treatment) relative to the NPS 2143-treated animals in the face of maintained elevation of bone formation (Figure 7).

These changes in histomorphometric indices of bone formation and resorption and in cancellous bone content were reflected by changes in BMD in the distal femur. BMD was $0.3725 \pm 0.0095 \mathrm{~g} / \mathrm{cm}^{2}$ in the shamoperated rats at baseline, and changed little (final value $0.3744 \pm 0.0068 \mathrm{~g} / \mathrm{cm}^{2}$ ) during the 5 -week treatment
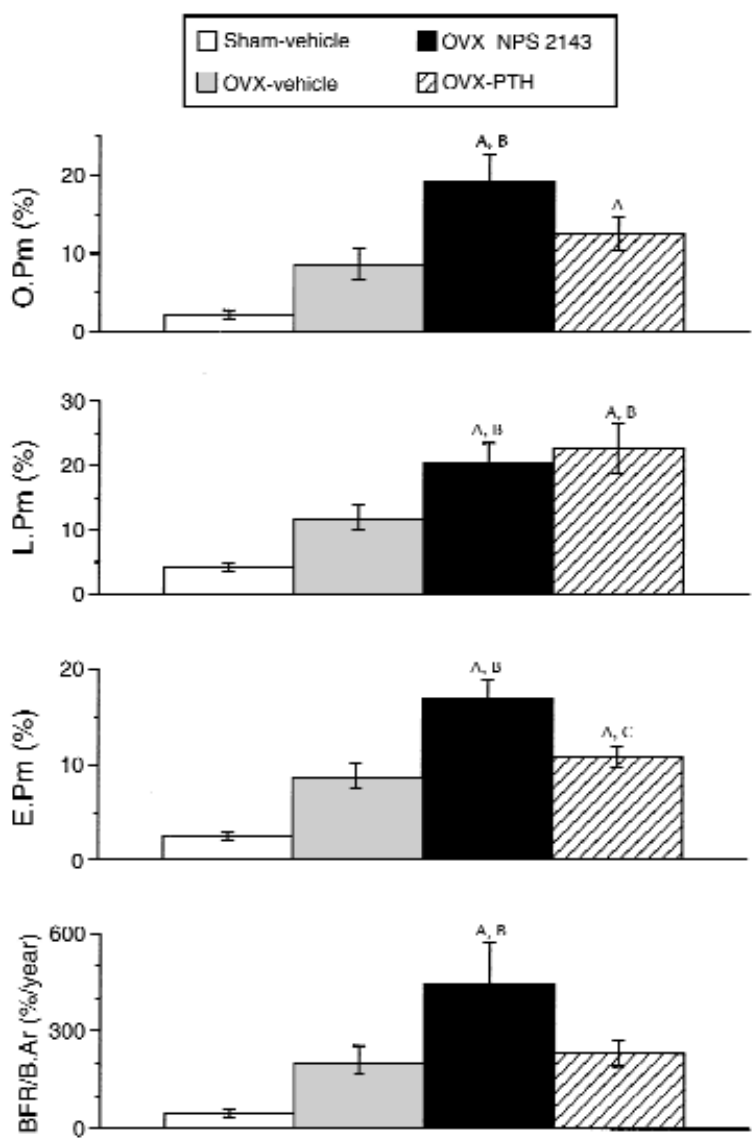

Figure 5

Histomorphometric analysis of cancellous bone in the proximal tibial metaphysis from osteopenic OVX rats treated daily for 8 weeks with NPS $2143(100 \mu \mathrm{mol} / \mathrm{kg}$, per os) or rat PTH(1-34) $(5 \mu \mathrm{g} / \mathrm{kg}$, subcutaneously). See Methods for abbreviations. Values are mean \pm SE; $n=10-14$ per group. ASignificantly different from sham-vehicle; $P<$ 0.05 . BSignificantly different from OVX-vehicle; $P<0.05$. 'Significantly different from OVX-NPS 2143; $P<0.05$. 


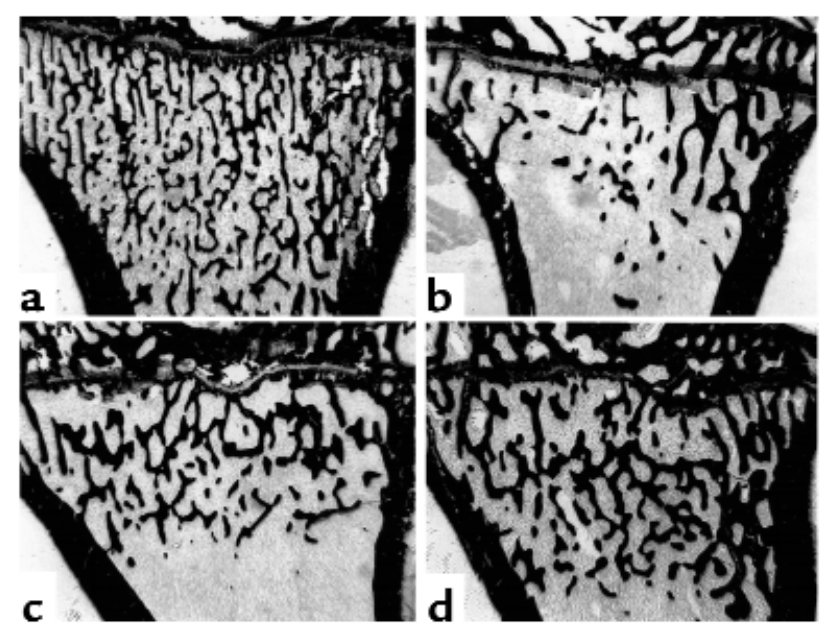

Figure 6

Sections of proximal tibia stained with von Kossa stain from OVX rats with established osteopenia, showing the anabolic effects on cancellous bone of daily oral administration for 5 weeks of NPS 2143 (100 $\mu \mathrm{mol} / \mathrm{kg}$ ) when given in combination with continuous subcutaneous infusion of $17 \beta$-estradiol. Shown are a sham-operated rat given vehicle (a), an OVX rat given vehicle (b), an OVX rat given $17 \beta$-estradiol alone (c), and an OVX rat treated with NPS 2143 and 17ß-estradiol (d).

period. BMD was substantially reduced in the OVX rats at baseline $\left(0.3134 \pm 0.0032 \mathrm{~g} / \mathrm{cm}^{2}\right)$, and was not significantly different between groups (Figure 8). BMD did not change significantly $(0.4 \pm 0.8 \%$ increase $)$ in vehicletreated OVX rats, and decreased slightly $(2.0 \pm 1.7 \%$ decrease) in rats given NPS 2143 alone. However, BMD increased $2.9 \pm 1.5 \%$ in rats given $17 \beta$-estradiol alone, and $7.2 \pm 1.4 \%$ in rats given NPS 2143 and $17 \beta$-estradiol. The magnitude of the increase in BMD in rats given the combination of $17 \beta$-estradiol and NPS 2143 was significantly greater $(P<0.02)$ than in rats given estradiol alone.

\section{Parathyroid cell proliferation}

Approximately 6,000 cells from three separate sections from both parathyroid glands were evaluated for BrdU uptake in each rat. The rate of cell proliferation in the parathyroid glands of the animals in this study was low.
On average, only about 30 of the 6,000 cells $(0.5 \%)$ had divided during the last 4 days of the study (Figure 9). In contrast, in the ileum, almost $100 \%$ of surface epithelial cells and about $30 \%$ of cells within the central compartment of the villus had taken up BrdU (not shown). The rate of cell division was not significantly affected by ovariectomy or by treatment with $17 \beta$-estradiol, NPS 2143, or both.

NPS 2143 has no direct effects on osteoblasts and osteoclasts in vitro

Osteoblast activity. Whereas PTH caused a 2.6-fold increase in cyclic AMP levels in TF274 osteoblastic cells, NPS $2143(0.1-10.0 \mu \mathrm{mol} / \mathrm{L})$ had no effect on either basal or PTH-induced cyclic AMP levels (Figure 10a). Essentially identical results were seen in primary human osteoblasts (not shown). PTH treatment of TF274 cells increased alkaline phosphatase activity 7.6fold; the addition of NPS $2143(0.01-1.0 \mu \mathrm{mol} / \mathrm{L}) \mathrm{did}$ not affect either basal or PTH-stimulated activity (Figure 10b). NPS $2143(10 \mu \mathrm{mol} / \mathrm{L})$ tended to reduce the alkaline phosphatase response to PTH in TF274 cells, although this is more likely to be a result of cellular toxicity at this very high concentration.

Osteoclast activity. NPS 2143 had no effect on bone resorption by isolated human osteoclasts plated on bovine cortical bone particles at concentrations up to $3 \mu \mathrm{mol} / \mathrm{L}$. In contrast, an inhibitor of cathepsin K, SB240314 (28), inhibited this production with an $\mathrm{IC}_{50}$ of $0.9 \mu \mathrm{mol} / \mathrm{L}$. This assay is limited by its sensitivity to DMSO, so concentrations of NPS 2143 above $3 \mu \mathrm{mol} / \mathrm{L}$ could not be tested. In the fetal rat long bone assay, NPS 2143 inhibited resorption significantly, with an $\mathrm{IC}_{50}$ of $11.3 \pm 3.0 \mu \mathrm{mol} / \mathrm{L}$.

\section{Discussion}

We have demonstrated that an orally active calcilytic compound can be designed that blocks the parathyroid $\mathrm{Ca}^{2+}$ receptor and thereby raises plasma PTH to levels that are sufficient to stimulate bone turnover. The pharmacokinetic characteristics of this molecule are such that, after oral administration, a prolonged elevation of PTH (> 4 hours) is obtained. In contrast, when PTH was elevated for up to 2 hours after PTH injection, bone

Table 1

Effect of administration of $17 \beta$-estradiol and NPS 2143 on cancellous bone in the proximal tibial metaphysis of OVX rats with established osteopenia

\begin{tabular}{cccccc}
\hline Surgery & Treatment & Tb.Ar $(\%)$ & Tb.Th $(\mu \mathrm{m})$ & Tb.N $\left(\mathrm{mm}^{-1}\right)$ & Tb.Sp $(\mu \mathrm{m})$ \\
Sham & Vehicle & $35.9 \pm 1.7$ & $67.2 \pm 2.3$ & $5.33 \pm 0.13$ & $175 \pm 8$ \\
OVX & Vehicle & $9.9 \pm 1.7^{\mathrm{A}}$ & $60.9 \pm 3.2$ & $1.57 \pm 0.23^{\mathrm{A}}$ & $1193 \pm 331^{\mathrm{A}}$ \\
OVX & Estradiol & $14.8 \pm 1.9^{\mathrm{A}}$ & $58.3 \pm 1.7$ & $2.50 \pm 0.30^{\mathrm{A}, \mathrm{B}}$ & $716 \pm 250$ \\
OVX & NPS 2143 & $8.6 \pm 0.9^{\mathrm{A}}$ & $56.6 \pm 2.5^{\mathrm{A}}$ & $1.50 \pm 0.15^{\mathrm{A}, \mathrm{C}}$ & $951 \pm 100^{\mathrm{A}}$ \\
OVX & Estradiol & $20.7 \pm 4.3^{\mathrm{A}, \mathrm{B}, \mathrm{D}}$ & $73.0 \pm 5.7^{\mathrm{B}, \mathrm{C}, \mathrm{D}}$ & $2.75 \pm 0.51^{\mathrm{A}, \mathrm{B}, \mathrm{D}}$ & $557 \pm 99^{\mathrm{B}}$ \\
& NPS 2143 & & & &
\end{tabular}

Values are mean \pm SE, $n=9-10$ per group. See Methods for abbreviations. ASignificantly different from sham-vehicle; $P<0.05$. BSignificantly different from OVXvehicle; $P<0.05$. 'Significantly different from OVX-estradiol; $P<0.05$. DSignificantly different from OVX-NPS $2143 ; P<0.05$. 

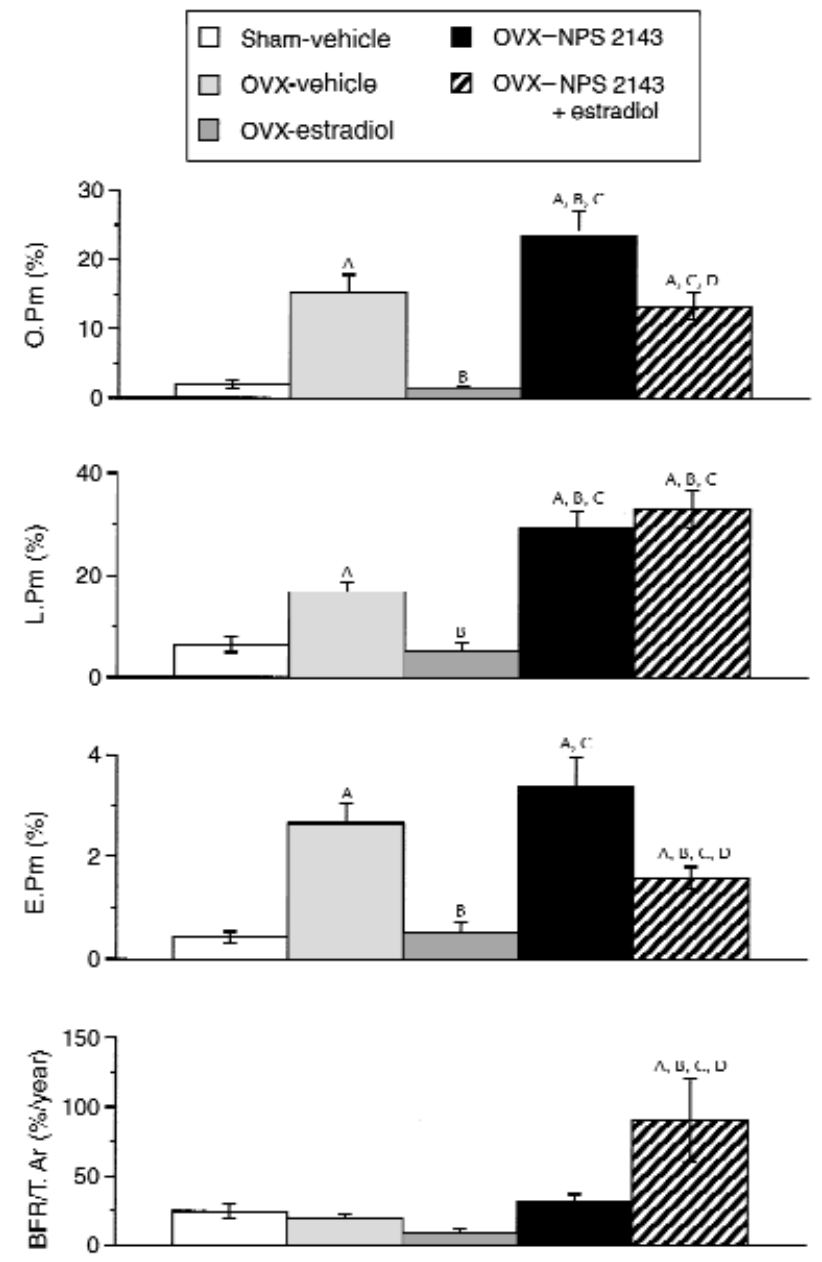

Figure 7

Histomorphometric analysis of cancellous bone in the proximal tibial metaphysis from osteopenic OVX rats treated daily for 5 weeks with $17 \beta$-estradiol (continuous subcutaneous infusion), NPS 2143 (100 $\mu \mathrm{mol} / \mathrm{kg}$, per os.), or NPS 2143 and $17 \beta$-estradiol. See Methods for abbreviations. Values are mean $\pm \mathrm{SE}, n=9-10$ per group. ASignificantly different from sham-vehicle; $P<0.05$. ${ }^{B}$ Significantly different from OVX-vehicle; $P<0.05$. 'Significantly different from OVX-estradiol; $P<0.05$. DSignificantly different from OVX-NPS 2143; $P<0.05$.

turnover was elevated but the balance was positive, resulting in net bone gain. When PTH was elevated to similar levels for longer than 4 hours in NPS 2143-treated animals, bone turnover was further elevated. However, both resorption and formation remained in balance, leading to no net loss or gain in bone mass.

It is well known that chronic elevation of PTH, such as that seen in hyperparathyroidism, leads to bone loss and abnormal bone histology $(33,34)$. Dobnig and Turner (35) showed that subcutaneous infusion of high doses of PTH $(40 \mu \mathrm{g} / \mathrm{kg}$ and $80 \mu \mathrm{g} / \mathrm{kg})$ over periods of 2 or more hours each day for 7 days led to rapid body weight loss, hypercalcemia, and histological abnormalities in the skeleton similar to those seen in patients with hyperparathyroidism. In our study, the much smaller increases in PTH, although sustained, did not lead to these adverse effects. It has been shown previously that substantial cancellous bone loss occurs in rats with mild sec- ondary hyperparathyroidism (two- to threefold increases in PTH levels) resulting from chronic renal insufficiency (34). Although an anabolic effect of PTH was not obtained with the more sustained exposure in the current study, the fact that bone loss was not exaggerated in rats given NPS 2143 suggests that the duration rather than the magnitude of the PTH response was insufficient to cause a worsening of the osteopenia. Indeed, plasma levels of PTH were normal, and NPS 2143 was undetectable in the circulation by 24 hours after the oral dose. This suggests that a shorter-acting compound that induces a more transient increase in PTH levels might induce a net anabolic effect on bone.

A further point of interest with regard to the amount of PTH secreted in response to NPS 2143 is the small magnitude of increase in PTH levels required to have profound effects on bone turnover. We showed previously that doses of rat PTH(1-34) as low as $1 \mu \mathrm{g} / \mathrm{kg}$ (which increase PTH levels by approximately threefold) increase bone formation in OVX rats (22). In contrast, most published studies on effects of PTH in rats have used a dose of $80 \mu \mathrm{g} / \mathrm{kg}$. When injected subcutaneously, this dose leads to a circulating level of approximately $10,000 \mathrm{pg} / \mathrm{mL}$ (35), compared with the $100-200 \mathrm{pg} / \mathrm{mL}$ in our studies. This clearly demonstrates that very small increases in the plasma levels of PTH are effective in stimulating bone metabolism. This is also illustrated by the much lower doses used in the clinical studies performed recently in which PTH doses of about $0.4-0.8 \mu \mathrm{g} / \mathrm{kg}$ body weight increased bone mass substantially (8-13). The 0.4 $\mu \mathrm{g} / \mathrm{kg}$ dose increased plasma levels of PTH(1-34) to approximately $90 \mathrm{pmol} / \mathrm{L}$ at 30 minutes after dosing

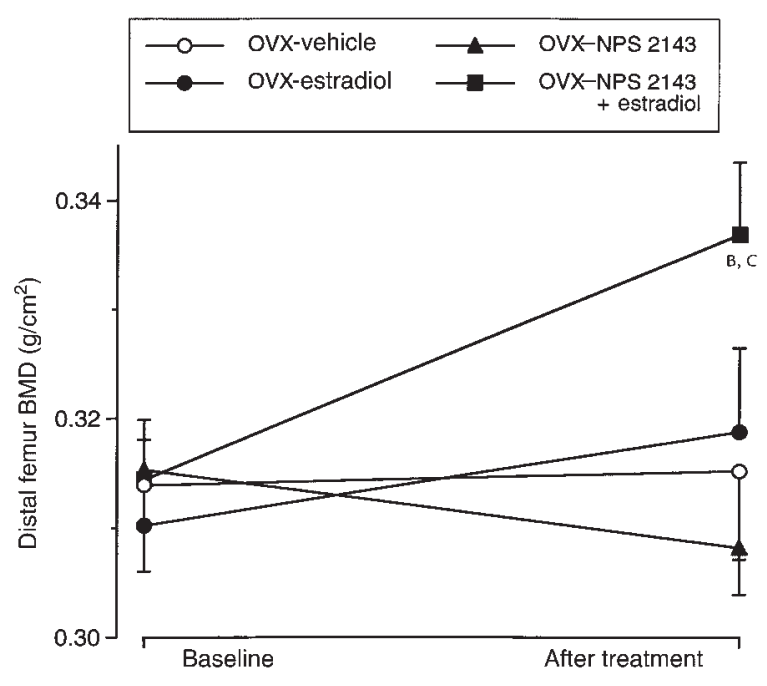

Figure 8

Effects of daily treatment of osteopenic OVX rats for 5 weeks with $17 \beta$-estradiol (continuous subcutaneous infusion), NPS 2143 (100 $\mu \mathrm{mol} / \mathrm{kg}$, per os), or NPS 2143 and $17 \beta$-estradiol on BMD in the distal femur. Values are mean \pm SE; $n=9-10$ per group. ${ }^{B}$ Significantly different from OVX-vehicle; $P<0.05$. CSignificantly different from OVX-NPS 2143; $P<0.05$ 


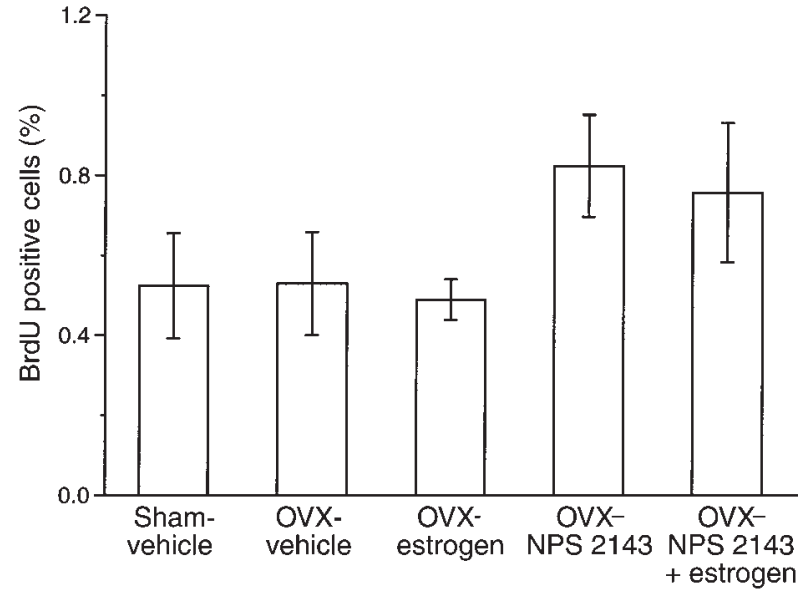

Figure 9

Absence of changes in cell proliferation in the parathyroid gland of osteopenic OVX rats treated daily for 5 weeks with $17 \beta$-estradiol (continuous subcutaneous infusion), NPS 2143 (100 $\mu \mathrm{mol} / \mathrm{kg}$, per $o s)$, or NPS 2143 and $17 \beta$-estradiol. Values are mean \pm SE; $n=4-5$ per group; $P=0.26$.

(36). This represents an approximately threefold increase over the baseline circulating level of endogenous PTH in these patients. Thus it appears that the repeated transient elevation of circulating PTH levels by a short-acting $\mathrm{Ca}^{2+}$ receptor antagonist are quite sufficient to cause an anabolic effect in bone.

One potential concern with repeated stimulation of the parathyroid gland is that it may induce parathyroid cell hyperplasia. It is well recognized that the parathyroid glands are larger in rats fed a low-calcium diet (37). Naveh-Many et al. (38) showed markedly increased parathyroid cell proliferation in weanling rats fed a low-calcium diet for 3 weeks. In contrast, Wernerson et al. (39) showed in older calcium-deficient rats that this glandular enlargement resulted exclusively from hypertrophy of the parathyroid cells, and not from hyperplasia. The results of our studies, showing that a hyperplastic response does not occur even with the extended duration of stimulation to parathyroid cells induced by treatment with NPS 2143 , are consistent with those of Wernerson et al.

Numerous studies have been performed in the OVX rat to determine whether concurrent antiresorptive treatment affects the anabolic effect of PTH. Studies have shown that the bone formation effect of PTH in OVX rats is not ablated by estrogen, calcitonin, or the bisphosphonate risedronate (40-43). However, one study did show an inhibition of bone turnover and a dramatic decrease in bone formation rate when the bisphosphonate tiludronate was used in conjunction with PTH in elderly ewes (44). The authors of that study suggested that bone turnover is required in order for PTH to have an anabolic effect. Our study showed that new bone formation occurred in the absence of previous resorption, which would appear to contradict those findings. It is possible that the effects in rats and sheep may be different. However, it is clear that in postmenopausal women, the anabolic effect of PTH is demonstrable in the presence of estrogen $(10,11,13)$. Our studies also suggest that even a long-acting calcilytic could have therapeutic benefits if administered concurrently with estrogen.

There have been reports of $\mathrm{Ca}^{2+}$ receptors on both osteoclasts and osteoblasts. Receptors that are both similar to $(45,46)$ and distinct from $(47)$ the one known receptor have been reported on osteoblasts in vitro. $\mathrm{Ca}^{2+}$ receptors have also been characterized pharmacologically on osteoclasts (48), but there is no evidence to suggest that this receptor is structurally similar to that on the parathyroid cell, and it is known to be distinct pharmacologically (49). Moreover, although previous studies have shown that NPS 2143 does not act on structurally similar metabotropic glutamate and $G_{A B A}$ receptors (23), it may act on other receptors. Particularly important in this regard are PTH receptors in bone. Any activity of a $\mathrm{Ca}^{2+}$ receptor antagonist on PTH receptors at this site could easily abolish the desired effect on bone and instead cause something quite undesirable. Indeed, actions of NPS 2143 on any of a number of different receptors expressed in bone could render this class of compounds therapeutically useless. For this reason, we examined the effects of NPS 2143 in a number of assays that monitor functional activity of bone cells in
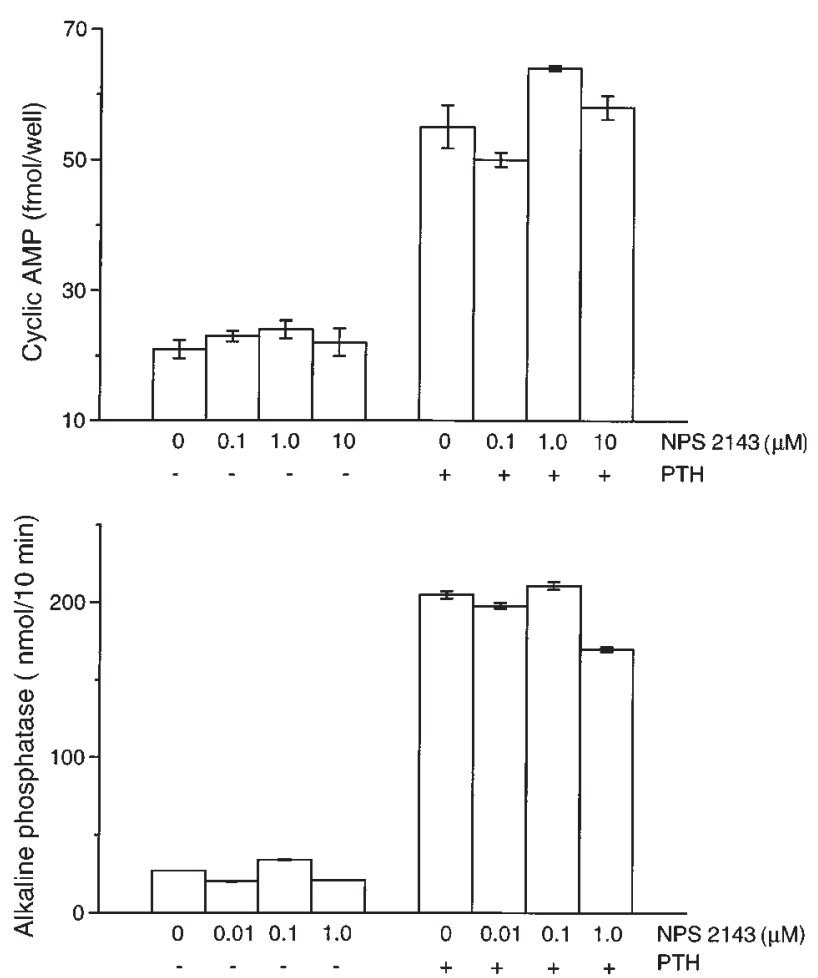

\section{Figure 10}

NPS 2143 does not affect basal or PTH-stimulated cyclic AMP formation or alkaline phosphatase activity in TF274 osteoblastic cells. Values are mean \pm SE of experiments performed in triplicate. 
vitro, both in the presence and absence of PTH. Of the five different assays used, only the fetal rat long bone assay detected an effect of NPS 2143. The inhibitory effect on resorption in this assay was not seen using isolated human osteoclasts, and even in the rat assay, inhibitory effects of NPS 2143 were seen only at concentrations $\left(\mathrm{IC}_{50}=11 \mu \mathrm{M}\right)$ far in excess of those required to block the parathyroid $\mathrm{Ca}^{2+}$ receptor $\left(\mathrm{IC}_{50}=\right.$ $0.043 \mu \mathrm{M})$. Taken together, the data suggest that NPS 2143, when used at concentrations that maximally inhibit $\mathrm{Ca}^{2+}$ receptor activity, does not affect bone cell activity. This suggests that the increased bone resorption seen in rats treated with NPS 2143 results solely from the prolonged exposure to elevated PTH levels.

It has not escaped our attention that the failure of a potent $\mathrm{Ca}^{2+}$ receptor antagonist to affect bone resorption in vitro probably has implications for the controversy regarding the presence (or absence) of the $\mathrm{Ca}^{2+}$ receptor in skeletal tissues (46-50). However, our data do not directly address this issue and therefore should not be used to support either argument. The pharmacological properties of receptors are known to differ depending on the cellular environment in which they are expressed (51). The $\mathrm{Ca}^{2+}$ receptor is no exception, and displays a very different pharmacology in $\mathrm{C}$ cells than in parathyroid cells, at least in response to $\mathrm{Ca}^{2+}$ receptor agonist (calcimimetic) compounds $(52,53)$.

In conclusion, we have provided proof-of-concept for the view that stimulation of endogenous PTH secretion using an antagonist of the parathyroid cell $\mathrm{Ca}^{2+}$ receptor results in increased bone formation and resorption. In the presence of an antiresorptive agent, NPS 2143 caused an increase in bone mass. These findings provide the basis for the development of calcilytics, a novel class of anabolic agents for the treatment of established osteoporosis.

\section{Acknowledgments}

The authors thank Sandra Hoffman, Peter Liang, Janice Vasco-Moser, Beata Lechowska, and Uma Prabhakar for excellent technical assistance, and Michael W. Lark, Larry J. Suva, and John C. Lee for editorial input.

1. Melton, L.J. 1995. Epidemiology of fractures. In Osteoporosis: etiology, diagnosis and management. 2nd edition. B.L. Riggs and L.J. Melton, III, editors. Lippincott Williams \& Wilkins Publishers. Philadelphia, Pennsylvania, USA. 225-247.

2. Ray, N.F., Chan, J.K., Thamer, M., and Melton, L.J., III. 1997. Medical expenditures for the treatment of osteoporotic fractures in the United States in 1995: report from the National Osteoporosis Foundation. $J$. Bone Miner. Res. 12:24-35.

3. Dempster, D.W., Cosman, F., Parisien, M., Shen, V., and Lindsay, R. 1993 Anabolic actions of parathyroid hormone on bone. Endocr. Rev. 14:690-709.

4. Reeve, J. 1996. PTH: a future role in the management of osteoporosis? J. Bone Miner. Res. 11:440-445.

5. Li, M., and Wronski, T.J. 1995. Response of femoral neck to estrogen depletion and parathyroid hormone in aged rats. Bone. 16:551-557.

6. Jerome, C.P. 1994. Anabolic effect of high doses of human parathyroid hormone (1-38) in mature intact female rats. J. Bone Miner. Res. 9:933-942.

7. Ejersted, C., Andreassen, T.T., Hauge, E.-M., Melsen, F., and Oxlund, H. 1995. Parathyroid hormone (1-34) increases vertebral bone mass, compressive strength, and quality in old rats. Bone. 17:507-511.

8. Slovik, D.M., et al. 1986. Restoration of spinal bone in osteoporotic men by treatment with human parathyroid hormone (1-34) and 1,25-dihydroxyvitamin D. J. Bone Miner. Res. 1:377-381.

9. Kurland, E.S., et al. 1998. Parathyroid hormone (PTH 1-34) increases cancellous bone mass markedly in men with idiopathic osteoporosis. Bone. 23(Suppl.):S158. (Abstr.)

10. Lindsay, R., et al. 1997. Randomised controlled study of effect of parathyroid hormone on vertebral-bone mass and fracture incidence among postmenopausal women on oestrogen with osteoporosis. Lancet. 350:550-555.

11. Hodsman, A.B., et al. 1997. A randomized controlled trial to compare the efficacy of cyclical parathyroid hormone versus cyclical parathyroid hormone and sequential calcitonin to improve bone mass in postmenopausal women with osteoporosis. J. Clin. Endocrinol. Metab. 82:620-628.

12. Lane, N.E., et al. 1998. Parathyroid hormone treatment can reverse corticosteroid-induced osteoporosis. J. Clin. Invest. 102:1627-1633.

13. Roe, E.B., et al. 1999. Parathyroid hormone 1-34 (hPTH 1-34) and estrogen produce dramatic bone density increases in postmenopausal osteoporosis. Results from a placebo-controlled randomized trial. J. Bone Miner. Res. 14(Suppl. 1):S137. (Abstr.)

14. Nemeth, E.F. 1996. Calcium receptors as novel drug targets. In Principles of bone biology. J.P. Bilezekian, L.G. Raisz, and G. Rodan, editors. Academic Press. San Diego, California, USA. 1019-1035.

15. Brown, E.M., et al. 1993. Cloning and characterization of an extracellular $\mathrm{Ca}^{2+}$-sensing receptor from bovine parathyroid. Nature. 366:575-580.

16. Garrett, J.E., et al. 1995. Molecular cloning and functional expression of human parathyroid calcium receptor cDNAs. J. Biol. Chem. 270:12919-12925.

17. Brown, E.M., Pollak, M., and Hebert, S.C. 1998. The extracellular calcium-sensing receptor: its role in health and disease. Annu. Rev. Med. 49:15-29.

18. Nemeth, E.F., and Fox, J. 1999. Calcimimetic compounds: a direct approach to controlling plasma levels of parathyroid hormone in hyperparathyroidism. Trends Endocrinol. Metab. 10:66-71.

19. Nemeth, E.F., et al. 1998. Calcimimetics with potent and selective activity on the parathyroid calcium receptor. Proc. Natl. Acad. Sci. USA. 95:4040-4045.

20. Silverberg, S.J., et al. 1997. Short-term inhibition of parathyroid hormone secretion by a calcium-receptor agonist in patients with primary hyperparathyroidism. N. Engl. J. Med. 337:1506-1510.

21. Antonsen, J.E., Sherrard, D.J., and Andress, D.L. 1998. A calcimimetic agent acutely suppresses parathyroid hormone levels in patients with chronic renal failure. Kidney Int. 53:223-227.

22. Fox, J., Miller, M.A., Stroup, G.B., Nemeth, E.F., and Miller, S.C. 1997. Plasma levels of parathyroid hormone that induce anabolic effects in bone of ovariectomized rats can be achieved by stimulation of endogenous hormone secretion. Bone. 21:163-169.

23. Nemeth, E.F., et al. 1998. Stimulation of parathyroid hormone secretion by a small molecule antagonist of the calcium receptor. Bone. 23:(Suppl.)156. (Abstr.)

24. Brown, E.M., Vassilev, P.M., Quinn, S., and Hebert, S.C. 1999. G-proteincoupled, extracellular $\mathrm{Ca}^{2+}$ sensing receptor: a versatile regulator of diverse cellular functions. Vitam. Horm. 55:1-71.

25. Villanueva, A.R. 1988. A new Goldner's one-step trichrome stain for identification of osteoid seams, bone and cells in undecalcified, plastic embedded sections of bone. Journal of Histotechnology. 11:249-251.

26. Parfitt, A.M., et al. 1987. Bone histomorphometry: standardization of nomenclature, symbols, and units. J. Bone Miner. Res. 2:595-610.

27. James, I.E., Dodds, R.A., Olivera, D.L., Nuttall, M.E., and Gowen, M. 1996. Human osteoclastoma-derived stromal cells: correlation of the ability to form mineralized nodules in vitro with formation of bone in vivo. J. Bone Miner. Res. 11:1453-1460.

28. Beresford, J.N., et al. 1984. The effects of monocyte-conditioned medium and interleukin 1 on the synthesis of collagenous and non-collagenous proteins by mouse bone and human bone cells in vitro. Biochim. Biophys. Acta. 801:58-65.

29. Gowen, M., MacDonald, B.R., and Russell, R.G. 1988. Actions of recombinant human $\lambda$-interferon and tumor necrosis factor $\alpha$ on the proliferation and osteoblastic characteristics of human trabecular bone cells in vitro. Arthritis Rheum. 31:1500-1507.

30. James, I.E., et al. 1999. Development and characterization of a human in vitro resorption assay: demonstration of utility using novel antiresorptive agents. J. Bone Miner. Res. 14:1562-1569.

31. Foged, N.T., et al. 1996. Quantification of the collagenolytic activity of isolated osteoclasts by enzyme-linked immunosorbent assay. J. Bone Miner. Res. 11:226-237.

32. Votta, B.J., and Bertolini, D.R. 1994. Cytokine suppressive anti-inflammatory compounds inhibit bone resorption in vitro. Bone. 15:533-538.

33. Silverberg, S.J., et al. 1995. Increased bone mineral density after parathyroidectomy in primary hyperparathyroidism. J. Clin. Endocrinol. Metab. 80:729-734.

34. Miller, M.A., Chin, J., Miller, S.C., and Fox, J. 1998. Disparate effects of mild, moderate, and severe secondary hyperparathyroidism on cancel- 
lous and cortical bone in rats with chronic renal insufficiency. Bone. 23:257-266.

35. Dobnig, H., and Turner, R.T. 1997. The effects of programmed administration of human parathyroid hormone fragment (1-34) on bone histomorphometry and serum chemistry in rats. Endocrinology. 138:4607-4612.

36. Lindsay, R., Nieves, J., Henneman, E., Shen, V., and Cosman, F. 1993. Subcutaneous administration of the amino-terminal fragment of human parathyroid hormone-(1-34): kinetics and biochemical response in estrogenized osteoporotic patients. J. Clin. Endocrinol. Metab. 77:1535-1539.

37. Ham, A.W., Littner, B.A., Drake, T.G.H., Robertson, E.C., and Tisdall, F.F. 1940. Physiological hypertrophy of the parathyroids, its cause and its relation to rickets. Am. J. Pathol. 16:277-286.

38. Naveh-Many, T., Rahamimov, R., Livni, N., and Silver, J. 1995. Parathyroid cell proliferation in normal and chronic renal failure rats. The effects of calcium, phosphate, and vitamin D. J. Clin. Invest. 96:1786-1793.

39. Wernerson, A., Widholm, S.M., Svensson, O., and Reinholt, F.P. 1991. Parathyroid cell number and size in hypocalcemic young rats. APMIS. 99:1096-1102.

40. Mosekilde, L., Søgaard, C.H., McOsker, J.E., and Wronski, T.J. 1994. PTH has a more pronounced effect on vertebral bone mass and biomechanical competence than antiresorptive agents (estrogen and bisphosphonate)-assessed in sexually mature, ovariectomized rats. Bone. 15:401-408.

41. Søgaard, C.H., Wronski, T.J., McOsker, J.E., and Mosekilde, L. 1994. The positive effect of parathyroid hormone on femoral neck bone strength in ovariectomized rats is more pronounced than that of estrogen or bisphosphonates. Endocrinology. 134:650-657.

42. Li, M., Mosekilde, L., Søgaard, C.H., Thomsen, J.S., and Wronski, T.J. 1995. Parathyroid hormone monotherapy and cotherapy with antiresorptive agents restore vertebral bone mass and strength in aged ovariectomized rats. Bone. 16:629-635.

43. Baumann, B.D., and Wronski, T.J. 1995. Response of cortical bone to antiresorptive agents and parathyroid hormone in aged ovariectomized rats. Bone. 16:247-253.

44. Delmas, P.D., et al. 1995. The anabolic effect of human PTH (1-34) on bone formation is blunted when bone resorption is inhibited by tiludronate: is activated resorption a prerequisite for the in vivo effect of PTH on formation in a remodeling system? Bone. 16:603-610.

45. House, M.G., et al. 1997. Expression of an extracellular calcium-sensing receptor in human and mouse bone marrow cells. J. Bone Miner. Res. 12:1959-1970.

46. Yamaguchi, T., Kifor, O., Chattopadhyay, N., and Brown, E.M. 1998. Expression of extracellular calcium $\left(\mathrm{Ca}^{2+}{ }_{\mathrm{o}}\right)$-sensing receptor in clonal osteoblast-like cell lines, UMR-106 and SAOS-2. Biochem. Biophys. Res. Commun. 243:753-757.

47. Quarles, L.D., Hartle, J.E., II, Siddhanti, S.R., Guo, R., and Hinson, T.K. 1997. A distinct cation-sensing mechanism in MC3T3-E1 osteoblasts functionally related to the calcium receptor. J. Bone Miner. Res. 12:393-402.

48. Zaidi, M., Adebanjo, O.A., Moonga, B.S., Sun, L., and Huang, C.L.-H. 1999. Emerging insights into the role of calcium ions in osteoclast regulation. J. Bone Miner. Res. 14:669-674.

49. Steffey, M.E., and Nemeth, E.F. 1993. Extracellular calcium-sensing receptors on osteoclasts and parathyroid cells are pharmacologically distinct. J. Bone Miner. Res. 8(Suppl. 1):S385. (Abstr.)

50. Pi, M., Hinson, T.K., and Quarles, L.D. 1999. Failure to detect the extracellular calcium-sensing receptor (CasR) in human osteoblast cell lines. J. Bone Miner. Res. 14:1310-1319.

51. Kenakin, T. 1995. Agonist-receptor efficacy I: mechanisms of efficacy and receptor promiscuity. Trends Pharmacol. Sci. 16:188-192.

52. Lavigne, J.R., et al. 1998. Stimulation of calcitonin secretion by calcium receptor activators: evaluation using a new, highly-sensitive, homologous immunoradiometric assay for rat calcitonin. Endocrine. 9:293-301.

53. Fox, J., Lowe, S.H., Conklin, R.L., Petty, B.A., and Nemeth, E.F. 1999. Calcimimetic compound NPS R-568 stimulates calcitonin secretion but selectively targets parathyroid gland $\mathrm{Ca}^{2+}$ receptor in rats. J. Pharmacol. Exp. Ther. 290:480-486. 